УДК: 615.851:7

\title{
АРТТЕРАПИЯ В СИСТЕМЕ МЕТОДОВ ПСИХОФИЗИЧЕСКОЙ РЕАБИЛИТАЦИИ
}

\author{
Раиса Чаланова ${ }^{1}$ \\ ${ }^{1}$ Винницкий государственный педагогический университет имени Михаила Коцюбинского, Винница, Украина, \\ rchalanova@gmail.com
}

https://doi.org/10.29038/2220-7481-2019-02-79-86

\begin{abstract}
Аннотации
Актуальность темы исследований. В системе восстановительно-оздоровительных мероприятий в современной медицине реабилитации уделяется специалистами все больше внимания. Достижение более високих результатов лечения больных в целом и повышение эффективности восстановительного лечения является адекватным запросом общества. Таким образом, поиск новых и усовершенствование известных методов реаабилитации является актуальным направлением исследований. Один из путей повышения эффективности реабилитационных мероприятий - мобилизация всех внутренних ресурсов организма. В этом отношении интерес представляет активация не только периферического звена, на котором в основном строится вся система реабилитации, но и стимуляция центрального, регулирующего звена с обязательным включением в полный цикл восстановительных процессов психологического компонента. Так как этим требованиям удовлетворяет арттерапия, для специалистов представляется целесообразным больше внимания уделить именно этому методу. Цель исследований. Работа раскрывает обоснование эффективности включения арттерапии в систему психофизической реабилитацции. Методы исследований. Материалом для проведення исследований явились современные источники научной литературы, в которых отражаются результаты исследований функционирования высших отделов нервной системы при применении различных направлений арттерапии. Результати. На основании анализа литературных данных установлена роль психологического компонента в патогенезе заболеваний различной этиологии и его значимость в системе реабилитационных мероприятий. Отмечается целесообразность подхода к рассмотрению системы восстановительного лечения как психофизической реабилитации. С этой точки зрения, арттерапия как элемент мощного психологического воздействия, безусловно, играет свою позитивную роль в стимуляции восстановительных процессов и является основанием для расширения показаний к ее применению в психофизической реабилитации. Bыводы. По результатам проведенного анализа литературных данных делается заключение о том, что позитивным механизмом воздействия арттерапии в процессе реабилитации является не только элемент творческой целенаправленной деятельности пациента, важны также эстетический компонент и способ отвлечения от негативного состояния. Доказанным является факт мобилизации способности головного мозга к высокой пластичности нейроструктур и активация сенсорно-моторных систем для создания новых нейронних сетей, которые реализуются под влиянием арттерапии, чем и объясняется достигаемый терапевтический эффект.
\end{abstract}

Ключевые слова: психофизическая реабилитация, арттерапия. нейропластичность.

Раїса Чаланова. Арттерапія в системі методів психофізичної реабілітації. Актуальність теми. У системі відновлювально-оздоровчих заходів сучасної медицини все більше уваги приділяють реабілітації. Досягнення більш значних результатів лікування в цілому й ефективність реабілітації є адекватним питанням суспільства. Щодо цього пошук нових та вдосконалення відомих методів реабілітації $є$ актуальним напрямом досліджень. Одним зі шляхів підвищення ефективності реабілітаційних заходів є мобілізація всіх внутрішніх ресурсів організму. Туг інтерес викликає активація не лише периферійної ланки, на якій переважно будується вся система реабілітаційних заходів, але й на стимуляції центральної, регулювальної ланки з обов'язковим уключенням у повний цикл відновлювальних процесів і психологічного компонента. Оскільки ці вимоги задовольняє арттерапія, фахівцям доцільно більше уваги приділити саме цьому методу. Мета дослідження. У роботі обгрунтовано ефективність уключення арттерапії в систему психофізичної реабілітації. Методи дослідження. Матеріалом для проведення досліджень стали сучасні джерела наукової літератури, у яких відображені результати дослідження функціонування вищих відділів нервової системи за застосування різних напрямів арттерапії. Результати. На підставі аналізу літературних джерел установлено роль психологічного компонента в патогенезі захворювань різної етіології та його значимість у системі реабілітаційних заходів. Відзначено доцільність розгляду системи відновлювального лікування як психофізичну реабілітацію. Щодо цього арттерапія як елемент міцного психологічного впливу, безумовно, відіграє свою позитивну роль у стимуляції відновлювальних процесів і може бути запропонована щодо поширеного застосування в психофізичній реабілітації. Висновки. За результатами проведенного аналізу літературних джерел робимо висновок, що позитивним механізмом впливу арттерапії в процесі реабілітації $є$ не лише елементом творчої цілеспрямованої діяльності пацієнта, важливі також естетичний компонент і спосіб уникнення негативних спогадів. 
Доведеним $є$ факт мобілізації здатності головного мозку до високої пластичності нейроструктур й активація сенсорно-моторних систем щодо утворення нових нейронних сітей, які реалізуються під впливом арттерапії, чим i пояснюється необхідний терапевтичний ефект.

Ключові слова: психофізична реабілітація, арттерапія, нейропластичність.

Raisa Chalanova. Art therapy in the System of Methods of Psychophysical Rehabilitation. Urgency of the Research. In the system of rehabilitation activities of modern medicine, much attention is paid to rehabilitation. Achieving better results in treatment of patients in general and improving the effectiveness of rehabilitation is an adequate request of the society. Thus, the search for new and improvement of known methods of rehabilitation is a relevant area of research. One of the ways to increase the effectiveness of rehabilitation measures is the mobilization of all internal resources of an organism. In this context, not only peripheral link activation is of great interest, on which, basically, the entire rehabilitation system is built, but also the stimulation of the central, regulatory link with obligatory inclusion of psychological component in full range of recovery processes. Since the art-therapy satisfies these requirements, it seems reasonable for specialists to pay more attention to this particular method. Objective of the Research. The study is devoted to substantiating the art therapy effectiveness and its inclusion in the system of psychophysical rehabilitation. Research Methods. Modern literature reflecting the results of study of nervous system functioning while using various trends of art therapy served the material for the study. Results. The role of psychological component in pathogenesis of diseases of various etiologies and its significance in the system of rehabilitation activities has been established. The system of rehabilitation treatment is considered to be a psychophysical rehabilitation. From this point of view, art therapy, as an element of powerful psychological impact, undoubtedly plays its positive role in stimulating recovery processes and is the basis for broadening indications for its use in psychophysical rehabilitation. Conclusions. According to the results of literary data analysis, the author concludes that positive mechanism of impact of art therapy in rehabilitation process is not only the element of the patient's creative purposeful activity, it's not only the aesthetic component and the way to distract from negative state. It is proved that mobilization of ability to high plasticity of brain's neural structures and activation of sensor and motor systems for new neural networks creation, which is influenced by art therapy, and therapeutic effect is achieved.

Key words: psychophysical rehabilitation, art therapy, neuroplasticity.

Вступ. Любые изменения в жизни человека сопровождаются таким тяжелым состоянием, как срыв динамического стереотипа. Естественные возрастные изменения, состояние стрессированности вследствие смены семейного или социального статуса, необходимости перемены места жительства или профессии, а также развитие тяжелых заболеваний или травм, как правило, являются причиной возникновения не только физических ограничений, но и провоцируют развитие тяжелых психических потрясений. В процессе формирования тактики восстановительного лечения для достижения более высокой его эффективности специалисты используют патогенетически ориентированные методы с учетом всех звеньев патологического процесса и его последствий. С этой точки зрения следует учитывать и психологический компонент патогенеза соматических заболеваний и травматической болезни, а также значительную роль этого компонента в динамике выздоровления. Признание патогенетической роли психологического фактора и значение его коррекции для успешности лечения обосновывает целесообразность подхода к формулированию восстановительного лечения как психофизической реабилитации.

Целью проведенных исследований явилось обоснование целесообразности учета психологического компонента в патогенезе соматических заболеваний и заболеваний травматической этиологии и возможности эффективной его коррекции с использованием методов арттерапии.

Материал и методы исследования. Материалом для проведения исследований в соответствии с поставленной целью явились данные современной научной литературы, в которых отражаются результаты анализа наличия психологических отклонений при различных заболеваниях и травмах и обоснование эффективности применения методов арттерапии в системе восстановительного лечения.

Результаты. Вызванные кардинальными причинами изменения социального статуса, снижение уровня материального обеспечения, ограничение степени физической свободы, сужение возможностей личностной реализации побуждают пострадавших к переосмыслению узловых житейских позиций в создавшихся неблагоприятных условиях и инициируют необходимость глубоких личностных перемен, что на фоне снижения самооценки может явиться причиной усиления психоэмоционального напряжения вплоть до его срыва.

Особенно острой на сегодняшний день является проблема реабилитации военнослужащих, участников антитеррористической операции (АТО), что связано с необходимостью восстановления не только их физического состояния, но и социально-профессионального положения. По данным, представленным Украинским государственным медико-социальным центром ветеранов войны, из всего числа пролеченных пострадавших с повреждениями опорно-двигательного аппарата госпитализировали 52,7 \% пациен- 
тов. Повреждения нервной системы (невропатии, радикулопатии, последствия черепно-мозговой травмы) диагностированы у 33,2 \% пострадавших [20]. Психическими расстройствами (реакция на стресс, дезадаптация, ПТСР, психосоматические состояния) страдали $14,1 \%$ пациентов. В структуре последствий черепно-мозговой травмы авторы выделили астенический синдром $(38,9 \%)$, тревожно-фобический синдром (26,7 \%), истероидные формы (10,9\%), депрессии (23,1\%) [20].

Согласно данным, представленным А. А. Галаченко (2016), заболевания опорно-двигательного аппарата также сопровождаются нарушениями психической сферы. При этом тревожно-депрессивный синдром установлен у $45 \%$ пострадавших, тревожно-фобический - у $20 \%$, астеноневротический - у $20 \%$. Астенодепрессивный синдром выявлен у 15 \% больных с различными повреждениями опорно-двигательного аппарата, с чем связываем высокий уровень неудовлетворительных результатов лечения [6].

Тревогу медиков вызывает и рост психосоматических заболеваний в Украине. В структуре психосоматической патологии ученые выделяют три категории: конверсионные симптомы, функциональные синдромы и психосоматозы, включающие в себя такие серьезные заболевания, как гипертоническая болезнь, сахарный диабет, язва желудка, бронхиальная астма, нейродермиты, тиреотоксикоз, ишемическая болезнь сердца и др. [18].

К настоящему времени разработаны и широко используются высокоэффективные методы реабилитации и физического, и психического статуса пациентов. Совершенствование лечебно-восстановительных методик динамично возрастает. Однако данные свидетельствуют о высоком уровне неудовлетворительных результатов, уровень которых в лечении патологии опорно-двигательного аппарата достигает $40 \%$ [6]. Подчеркивается, что актуальной является разработка комплексных программ психологического сопровождения больных с этой патологией [6].

В плане разработки тактики реабилитационных мероприятий можно выделить проблемы, имеющие исключительно психологический характер и комбинированные состояния, при которых психологические отклонения, как правило, сопровождают нарушения физического статуса. Признавая наличие психологический отклонений, возникающих у больных с заболеваниями различной этиологии и травмами, система реабилитационных мероприятий, не может быть ограниченной только методами физической реабилитации. При проведении восстановительного лечения необходимо заботиться и о коррекции психического статуса пациента, что, безусловно, должно повысить общие результаты лечения. При обсуждении вопроса тактики восстановительного лечения точнее было бы определить его термином «психофизическая реабилитация».

В разработке тактики лечения любых заболеваний следует учитывать, что процесс излечения находится в зависимости не только от уровня оказания специализированной помощи. Важную роль в достижении максимально возможного позитивного результата лечения играет личностная характеристика пациента, уровень его мотивированности, нацеленной на достижение независимости и, как можно более широкой степени внутренней и внешней свободы. Мотивация к достижению таких целей во многом зависит от мировоззрения, уровня образованности, опыта предыдущей жизни пациента. В зависимости от многих исходных данных, физического и психического состояния, для пострадавшего может оказаться привлекательным состояние «выученной беспомощности», которое позволяет «спрятаться» от необходимости принимать какие-то решения и совершать активные действия, направленные на достижение выздоровления. Удобным и приятным может оказаться возможность привлечь к себе и своему состоянию повышенное внимание окружающих близких людей и воспользоваться оправданным уклонением от житейских обязанностей.

Не менее проблемной для исхода любой патологии является установка больного на бессмысленность и бесперспективность усилий, направленных на восстановительное лечение. Крайне негативная убежденность относительно целесообразности и эффективности лечебных мероприятий практически исключает вовлечение личности самого пациента в достижение его собственного здоровья.

Рассматривая вопрос участия психологического компонента в поддержании здоровья человека, в развитии ряда серьезных заболеваний и его участии в выздоровлении обращает на себя внимание утверждение О. В. Соловьева (2010) о том, что «в условиях средовой новизны безусловные рефлексы не способны «замкнуть» сенсорный вход и двигательный выход в единый информационный комплекс». В этом случае, по мнению автора, «психический процесс является системообразующим фактором нейронной активности, который осуществляет уже не физическую, но информационную связь сенсорного входа и двигательного выхода» [25]. Согласно современным представлениям, нейронная сеть является генетически сформированными нейронными «каналами» для беспрепятственного прохождения биоэлектрических сигналов от сенсорных структур к адекватным данному раздражителю двигательным ансамб- 
лям [26]. Нейронные сети, которые обеспечивают реализацию безусловно-рефлекторного ответа, идеально приспособлены выполнять информационные функции при неизменности среды. Утверждение, выдвинутое О. В. Соловьевым (2010), позволяет предположить, что коррекция психологического фона существенным образом может повлиять на течение и исход патологического процесса путем создания и закрепления новых нейронных сетей. Учитывая позитивное влияние всех видов искусства на психологический гомеостаз человека целесообразно шире включать в комплексную терапию различных патологических состояний методы арттерапии.

Следует отметить, что развитие арттерапи как метода лечения уже имеет почти столетнюю историю $[9 ; 16]$. Эффективность арттерапии в комплексном лечении ряда заболеваний не вызывает сомнений, что подтверждает развернутая сеть медицинских уреждений во всем мире, широко использующих методы арттерапии в лечебной практике, и организованая система учебных заведений, обучающих различным видам этого направления лечения [17]. В научной литературе есть сведения о применении арттерапии и в Украине $[1 ; 3 ; 5 ; 8 ; 9 ; 14 ; 22 ; 27]$. Наибольшее распространение арттерпия получила в лечении неврологических и психических заболеваний $[7 ; 13 ; 14 ; 1516 ; 17 ; 23]$. Гораздо меньше сведений об использовании методов арттерапии в лечении заболеваний других физиологических систем организма $[3 ; 5 ; ; 19 ; 24]$.

Как сборное понятие арттерапия включает в себя четыре основные модальности: арттрапия посредством изобразительного творчества, драматической, танцевально-двигательной и музыкальной терапии [9]. Эффективность драматического направления арттерапии может быть обоснована тем, что в структурах мозга зафиксированы аналогичные изменения в ответ на реальные и воображаемые раздражители $[4 ; 21]$. При применении драматического направления арттерапии выявлены такие позитивные эффекты, как коррекция идентификации, реализация креативного потенциала, улучшение эмоционального контроля, У больных с психическими заболеваниями этот метод применен с целью когнитивной тренировки, потенцирования невербальних взаимодействий и снятия ограничений с мотивационных ресурсов [13].

Включение танца в комплексную лечебную систему различных патологических состояний базируется на объединении нескольких позитивних воздействий: активации работы мозга путем тренировки пластичности нейронних сетей под влиянием ритмических и тембровых характеристик музики в сочетании с двигательной активностью и рализацией психокорригирующих эффектов коллективного творчества [2;27].

Наибольший объем. публикаций посвящен применению музыкотерапии. Установлена эффективность лечения с применением этого направления арттераии при психических заболеваниях [1; 15], заболеваниях нервной системы [1; 15; 19], при гипертонической болезни [3], Позитивный эффект музыкотерапии находит объяснение в выдвинутой гипотезе о вибрационной основе организации человека $[2 ; 10]$. При воздействии музыки на организм человека возникает совпадение алгоритмов колебаний, формирующих музыкальный звук и вибрацию структур человеческого организма на клеточном уровне $[1 ; 15]$. С позиции вибрационной теории можно объяснить установленные авторами синхронизирующее влияние музыки на лимбико-ретикулярные структуры, активацию спектра $\alpha$-ритма, выявленную преимущественно в передних отделах головного мозга, и снижение активности надсегментарных эрготропных симпатических влияний в реализации висцеральных функций [15]. В результате проведенных исследований под влиянием музыкального воздействия выявлены параметры, свидетельствующие о реорганизации полей биопотенциалов мозга. При этом сформулировано предположение о том, что изменение функционального состояния человека под влиянием музыки объясняется не столько влиянием специфической сенсорной стимуляции на определенные корковые поля и подкорковые структуры, сколько ее релаксирующими и гармонизирующими воздействиями на базисные интегративные процессы [28].

Активными параметрами биологического воздействия являются частота вибраций, тембр, громкость музыкальных тонов [1]. Телесно-ментальные и психосоматические эффекты, возникающие в организме под влиянием музыки, инициируют процессы, которые обусловлены прямыми акустическими резонансными откликами со стороны клеток, органов и систем и которые авторы рассматривают как динамический фактор регуляции саногенеза [1].

В результате проведенных исследований арттерапевты пришли к заключению о том, что музыка, написанная в соответствии с законами гармонии, поддерживает в организме антистрессовые реакции [3]. Согласно опубликованным данным, антиадренэргические и антистрессовые эффекты реализуются за счет позитивных влияний на функцию вегетативной нервной системы. Установлено, что при проведении 
музыкотерапии улучшение показателей функции сердечно-сосудистой системы происходит на фоне снижения биохимических показателей маркеров стрессированности (норадреналина, АКТГ, кортизола, лептина, двуокиси углерода). При этом у больных, страдающих гипертонической болезнью, отмечается снижение тревожности, улучшение качества сна, нормализация показателей сердечной деятельности и снижение артериального давлении [3].

При изучении эффективности арттерапии в направлении изобразительного искусства, О. И. Осокина и соавт. (2017) выделили и сформулировали следующие основные ее функции, на которых основан позитивный терапевтический результат лечения больных с психоневрологическими заболеваниями [23]. Этот обширный перечень включает такие эффекты, как:

- идентификация личности пациента и повышение его самооценки; дистанцирование от болезни;

- возможность открытого самовыражения даже тех состояний, которые трудно осознать и вербализировать; развитие сенсомоторных и коммуникативных навыков;

- совершенствование ассоциативного мышления, тренировка внимания и памяти; ощущение больными границ своего личного пространства, контроль этих границ;

- осознание и прочувствование целостности частей своего «я»; снятие тревоги, эмоционального напряжения.

По мнению ученых, при помощи изобразительного направления арттерапии создаются благоприятные ситуации, в которых пациенты начинают лучше понимать себя, свои переживания, свою уникальность и в то же время некоторую общность проблематики среди членов группы; видение смысла своих переживаний и возможность интеграции своего прошлого и настоящего опыта. Лечебная функция арттерапии, таким образом, по мнению указанных выше ученых, заключается в удовлетворении потребностей в самопонимании и положительном принятии себя; творческом и осмысленном времяпрепровождении; самовыражении и самосовершенствовании, выражении социально неприемлемых чувств и мыслей [23].

Наряду с психотерапевтическими эффектами арттерапии изобразительного направления, А. И. Копытин (2002) выделяет позитиваные механизмы, посредством которых осуществляется воздействие арттерапевтических техник [17]. По мнению автора, именно под влиянием фактора художественной экспрессии при создании художественных образов и конкретизации их в некую символику, реализуется пролонгированный во времени процесс переосознания больным внутренних личностных характеристик, систематизация хаотичных мыслей и «выплескивание чувств». Ссылаясь на мнение Эрнста Криса (Кris, 1975), автор связывает процесс художественной экспрессии с проявлением творческого воображения, которое является высокоэффективным инструментом создания новых нейронных связей, в ситуации, когда мышление полностью растворяется в первичных психических процессах. При этом в процессе создания новых форм, прогрессивных концепций и образов создаются предпосылки для разрешения проблем на визуальном уровне.

Достижение вышеуказанных лечебных эффектов арттерапии благоприятно отразится на клиническом течении и исходах любого патологического состояния, поэтому желательно более широкое применение этого метода в практической лечебной деятельности. Таких же лечебных эффектов можно достичь и при помощи нейрографики. Оба эти метода объединяют единые нейрофизиологические механизмы, но есть основания полагать, что нейрографика как одно из новых направлений арттерапии обладает существенными преимуществами и может стать достаточно эффективным методом как при проведении лечения психических нарушений, так и соматических заболеваний и травм, сопровождающихся отклонениями психологического статуса. Этот метод более доступен для применения, так как не требует никаких особенных условий для его использования. Необходимое оборудование - лист бумаги и карандаш. Для его реализации не надо обладать художественным даром, чтобы воспроизводить на бумаге конкретные образы или быть способным использовать для этой цели какую-либо символику. Важным достоинством нейрографики (по сравнению с существующим методом арттерапии художественного направления) является четкая методология, следование которой и позволяет достигать позитивних эффектов в разрешении широкого диапазона вопросов: психокоррекции, снятия психологической напряженности, улучшения физического состояния, облегчения поиска необходимых важних решений [11].

Дискуссия. Анализ представленнях научных данных позволяет рассматривать наличие выявленного психологического компонента в качестве патогегнетического звена в развитии соматических и посттравматических заболеваний. Именно этот установленный факт побуждает к включению психологичес- 
ких методов лечения в комплексную терапию и систему реабилитационных мероприятий различных патологических состояний, а самовосстановительное лечение отнести к категории психофизической реабилитации. Целесообразность такого похода к восстановительному этапу лечения заключается в сосредоточении внимания специалистов на важном патогенетическом звене патологического процесса с целью включения адекватных психокорригирующих методов в систему реабилитационных мероприятий.

Следует также учитывать ту роль, которую выполняет психологический компонент в осуществлении реабилитации путем мобилизации внутренних ресурсов организма, направленных именно на реализацию восстановительных процессов утраченных функций в результате заболеваний и травм.

Представленные в научной литературе результаты исследований, посвященные изучению механизмов лечебного воздействия арттерапии, позволяют сделать вывод о функциональной неоднозначности деятельности сенсорних систем, которые выполняют не только роль связующего звена с окружающей средой, но и являются активними проводниками в системе формирования нових нейронних связей. Установлены структурные изменения в центральних отделах нервной системы, преобразование биополей и ритмов, выявляемые под воздействием различных направлений арттерапии, указывают на колоссальные восстановительные возможности организма человека. Разносторонная палитра воздайствий, которыми оперирует арттерапия, основывается на обновлении нейронних сетей с использованием высокоразвитого в них качества нейропластичности. Сенсорная стимуляция корковых полей и подкорковых структур головного мозга, которая достигается методами арттерапи, дает возможность мобилизовать центральное звено рефлекторной дуги, а инициированные последующие моторные реакции - закрепить сформированные новые нейронные «дорожки». Психологический компонент, по мнению О. В. Соловьева, играет роль энергоинформационного системообразующего звена [26], но, по-видимому, функция его и возможности несколько шире. Следует учесть мобилизующие эффекты и механизмы, активирующие мотивацию личности, реализация которых не возможна без участия психологического компонента.

С позициий опубликованных в научной литературе данных можно прийти к заключению о том, что применение методов арттерапии в лечении многих заболеваний и травм патогенетически обосновано и заслуживает пристального внимания практикующих специалистов, так как позволяет повысить эффективность лечения любой патологии.

Выводы. По результатам проведенного анализа литературных данных приходим к заключению о том, что, позитивным механизмом воздействия арттерапии в процессе реабилитации является не только элемент творческой целенаправленной деятельности пациента, важны также эстетический компонент и способ отвлечения от негативного состояния. Доказанным является факт мобилизации способности головного мозга к высокой пластичности нейроструктур и активация сенсорно-моторных систем для создания новых нейронних сетей, которые реализуются под. влиянием арттерапии, чем и объясняется достигаемый терапевтический эффект.

\section{Источники и литература}

1. Апанасенко Г. Л., Савельева-Кулик Н. А. Музыкальная терапия: история, современность и перспективы развития. Украӥнський медичний часопис. 2012. № 4 (90). С. 170-173.

2. Барбараш А. Н. Волновые процессы в живом: основы стерео генетики и физиологии мышлени. Одесса: ОМПОЛИС, 1998. 349 c,

3. Березуцкий В. И., Березуцкая М. С. Возможности музыкальной терапии в лечении артериальной гипертензии. Украӥнський кардіологічний журнал. 2017. № 5. С.105-111.

4. Бехтерева Н. П. Магия мозга и лабиринты жизни. Москва - Санкт-Петербург: Полиграфиздат.СОВА. 2007. $366 \mathrm{c}$.

5. Бурбела Е. І., Волянська Л. А., Стеценко В. В., Козак Д. В. Ефективність нейтралізації тривожності у дітей, які хворіють на бронхіальну астму. Вісник наукових досліджень. 2016. № 3. С. $33-35$.

6. Галаченко А. А. Особенности нарушений психической сферы у больных с патологией опорнодвигательного аппарата. Медииинская психология. 2016. Т.11, № 2 (42) С. 10-12.

7. Гасан-заде Л. А., Эфендиев И. Р. Кукольный театр как метод психосоциальной реабилитации в психиартрической. HeŭpoNews. 2013. № 10 (55). С. 14-16.

8. Герасименко С. І., Шатковская I. С., Тореховський А. І. Музика в анестезіології. Biomedical and biosocial anthropology . 2005. № 5. C.8-31.

9. Дедишина Л. Бачити, чути, жити. Фармащевт практик. 2015. 12 (142). С. 20-21

10. Долгуша В. В., Тихонов М. Н., Долгуша Л. В. Волновые взаимодействия в биологии и медицине. СанктПетрбург. 2012. 270 с.

11. Демиург О. Нейрографика, рисование со смыслом «Ribero». Москва, 2018. 230 с.

12. Жаворонкова Л. А., Жарикова А. В., Кушнир Е. М., Михайлова А. А. ЭЭГ маркеры организации вертикальной позы у здорових людей. Физиология человека. 2012. Т. 38, № 6, С. 53-62. 
13. Захаров Н. Б., Злоказова М. В., Соловьев А. Г. Театр-терапия как метод реаблитации больных шизофренией. Медико-соииальная експертиза и реабилитация. 2015. Т.18, № 1. С.50-54.

14. Ільницька Т. Арттерапія як ефективний метод реабілітації пацієнтів із захворюваннями психіки. НейроNews. 2015. № 10 (74). C. 6-8.

15. Казымов А. Г., Мамедов А. М., Алиева Д. М., Чабанова О. М. Вегетативные и психофизиологические кореляти эффектов музикотераии при неврологических расстройствах. Журнал неврологи и психиатрии им. С. С. Корсакова. 2018. № 10. Т. 112. С. 45-49.

16. Каяшева О. И. Техники арт-терапии в психологическом консультированиии клиентов. Психология в вузе. 2014. № 4. С.127-133.

17. Копытин А. И. Теория и практика арт-терапии. Теория практика арт-терапии. Санкт-Петербург: Питер, 2002. $358 \mathrm{c}$

18. Луцик В. В., Романюк В. Л. Особливості поширення психосоматичних розладів на рівенщині. Психофізіологічні та вісцеральні функиії в нормі і патології: матеріали V Міжнар. наук. конф. 6-8 жовт. 2010, Україна, Київ: тези доп. Київ, 2010. С. 113.

19. Малаховская В. В., Федорова Н. Г. Влияние методов лечебной физкультуры и активной музыкальной терапии на восстановление неврологических функций у пациентов, перенесших ишемический инсульт в отдаленый период. Мануальная терапія: науч.-практ. журн. 2013. №1 (49) . С. 13-20.

20. Матяш М. М. Імплементація сучасних технологій відновного лікування постраждалих в умовах особливого періоду М. М. Матяш. Міжнародний неврологічний журнал. 2017. № 2 (88). С. 135.

21. Махин С. А., Макаричева А. А., Луцюк Н. В., Павленко В. В. Исследования слуховом восприятии и имитации движений: взаимосвязь со свойствами личности, определяющими эмпатию. Физиология человека. 2015. Т. 41, № 6. С. 28-35.

22. Місяк С. Л. Практичне використання музичної терапії як складника комплексної реабілітації онкологічних хворих/інвалідів. Фітотерапія. 2016. № 2. С. 16-17.

23. Осокина О. И. Арт-терапия в комплексном лечении больных с хроническими психоневрологическими заболеваниями. Международный неврологический журнал. 2017. № 2 (88). С. 106-113.

24. Попкова Г. Г. Силантьева В. А. Арт-терапия в психологической реабилитации детей, больных туберкулезом. Туберкулез и болезни легких. 2014. № 8. С. 88-89.

25. Соловьев О. В. Психический процесс как необходимый фактор переработки информации в нейросетях человеческого мозга. Нейронаука для медицины и психологии: материалы Шестого Международного Междисциплинарного конгресса. Судак, Крым, Украина, 5-15 июня 2010 г. С. 274.

26. Соловьев О. В., Бекова Е. А., Зейналов Э. С. О специфике управляющее-управляемых (детерминистских) связей в иерархиях нейросетей, реализующих психические процессы. Нейронаука для медицины и nсихологии: материалы Шестого Междунар. междисциплинарного конгресса. Судак, Крым, Украина, 515 июня 2010 г. С. 275.

27. Федий О. А. Естетотерапія. Київ, 2007. 247 с.

28. Шеповальников А. Н., Егоров М. В. Изменение пространственной организации колебаний биопотенциалов коры больших полушарий мозга у детей под влиянием музыки. Физиология человека. 2015. Т. 41, № 6. C. $5-16$.

\section{References}

1. Apanasenko, G. L., Savelieva-Kulik, N. A. (2012). Muzykalnaia terapiia: istoriia, sovremennost i perspektivy razvitiia. Ukrayinskyi medychnyi chasopys, 4 (90), 170-173.

2. Barbarash, A. N. (1998). Volnovye protsessy v zhivom: osnovy stereo genetiki i fiziologii myshleniia. Odessa: «OM-POLIS, 349.

3. Berezutskii, V. I., Berezutskaia, M. S. (2017). Vozmozhnosti muzykalnoi terapii v lechenii arterialnoi gipertenzii. Ukrayinskyi kardiologichnyi zhurnal, 5, 105-111.

4. Behtereva, N. P. (2007). Magiia mozga i labirinty zhizni. Moskva; Sankt-Peterburg: Poligrafizdat. SOVA, 366.

5. Burbela, E. I., Volianska, L. A., Stetsenko, V. V., Kozak, D. V. (2016). Efektyvnist neitralizatsiyi tryvozhnosti u ditey, yaki hvoriiut na bronhialnu astmu. Visnyk naukovyh doslidzhen, 3, 33-35.

6. Galachenko, A. A. (2016). Osobennosti narushenii psihicheskoi sfery u bolnyh s patologiei oporno-dvigatelnogo apparata. Meditsinskaia psihologiia, 11, 2 (42), 10-12.

7. Gasan-zade, L. A., Efendiev, I. R. (2013). Kukolnyi teatr kak metod psihosotsialnoi reabilitatsii v psihiartricheskoi praktike, NeiroNews, 10(55), 14-16.

8. Gerasymenko, S. I., Shatkovskaia, I. S., Torehovskyi, A. I. (2005). Muzyka v anesteziologiyi. Biomedical and biosocial anthropology, 5, 8-31.

9. Dedyshyna L. (2015). Bachyty, chuty, zhyty. Farmatsevt praktyk, 12 (142), 20-21

10. Dolgusha, V. V., Tihonov, M. N., Dolgusha, L. V. (2012). Volnovye vzaimodeistviia v biologii i meditsine. SanktPetersburg, 270.

11. Demiurg, O. (2018). Neirografika, risovanie so smyslom. «Ribero», 230. 
12. Zhavoronkova, L. A., Zharikova, A. V., Kushnir, E. M., Mihailova, A. A. (2012). EEG markery organizatsii vertikalnoi pozy u zdorovyh liudei. Fiziologiia cheloveka, 38, 6, 53-62.

13. Zaharov, N. B., Zlokazova, M. V., Soloviev, A. G. (2015). Teatr-terapiia kak metod reabilitatsii bolnyh shizofreniei. Mediko-sotsialnaia ekspertiza i reabilitatsiia, 18, 1, 50-54.

14. Ilnytska, T. (2015). Art-terapiia yak efektyvnyi metod reabilitatsiyi patsientiv iz zahvoriuvanniamy psyhiky. NeyroNews, 10 (74), 6-8.

15. Kazymov, A. G., Mamedov, A. M., Alieva, D. M., Chabanova, O. M. (2018). Vegetativnye i psihofiziologicheskie koreliati effektov muzykoteraii pri nevrologicheskih rasstroystvah. Zhurnal nevrologii i psihiatrii im. S. S. Korsakova, 10, 112, 45-49.

16. Kaiasheva, O. I. (2014). Tehniki art-terapii v psihologicheskom konsultirovanii klientov. Psihologiia v vuze, 4, 127133.

17. Kopytin, A. I. (2002). Teoriia i praktika art-terapii. Teoriia praktika art-terapii. Sankt-Peterburg: «Piter», 358.

18. Lutsyk, V. V., Romaniuk V. L. (2010). Osoblyvosti poshyrennia psyhosomatychnyh rozladiv na Rivnenschyni. V Mizhnarodna naukova konferentsiia. «Psyhofiziologichni ta vistseralni funktsiyi v normi i patologiyi», 6-8 zhovtnia 2010, Ukrayina, Kyiv: Tezy dopovidei, 113.

19. Malahovskaya, V. V., Fedorova N. G. (2013). Vliianie metodov lechebnoi fizkultury i aktivnoi muzykalnoi terapii na vosstanovlenie nevrologicheskih funktsii u patsientov, perenesshih ishemicheskii insult $\mathrm{v}$ otdalennyi period. Manualnaia terapiia. Nauchno-prakticheskii zhurnal, 1 (49), 13-20.

20. Matiash, M. M. (2017). Implementatsiia suchasnyh tehnologii vidnovnogo likuvannia postrazhdalyh v umovah osoblyvogo periodu M. M. Matiash. Mizhnarodnyi nevrologichnyi zhurnal, 2 (88), 135.

21. Makhin, S. A., Makaricheva A. A., Lutsiuk N. V., Pavlenko V. V. (2015). Issledovaniia $\mu$-ritma pri nabliudenii, slukhovom vospriiatii i imitatsii dvizhenii: vzaimosviaz so svoistvami lichnosti, opredeliaiushchimi empatiiu. Fiziologiia cheloveka, 41, 6, 28-35.

22. Misiak, S. L. (2016). Praktychne vykoristannia muzychnoyi terapii yak skladnyka kompleksnoyi reabilitatsiyi onkologichnykh khvorykh/invalidiv. Fitoterapiia, 2, 16-17.

23. Osokina, O. I. (2017). Art-terapiia v kompleksnom lechenii bolnykh s khronicheskimi psikhonevrologicheskimi zabolevaniiami. Mezhdunarodnyi nevrologicheskii zhurnal, 2 (88), 106-113.

24. Popkova, G. G. Silantieva, V. A. (2014). Art-terapiia v psikhologicheskoi reabilitatsii detei, bolnykh tuberkulezom. Tuberkulez i bolezni legkikh, 8, 88-89.

25. Soloviev, O. V. (2010). Psikhicheskii protsess kak neobkhodimyi faktor pererabotki informatsii v neirosetiakh chelovecheskogo mozga. Shestoi Mezhdunarodnyi Mezhdistsiplinarnyi kongress. "Neironauka dlia meditsiny $i$ psikhologii». Sudak, Krym, Ukraina, 5-15 iiunia, 274.

26. Soloviev, O. V., Bekova, E. A., Zeinalov, E. S. (2010). O spetsifike upravliaiushchee-upravlyaemykh (deterministskikh) sviazei v ierarkhiiakh neirosetei, realizuiushchikh psikhicheskie protsessy. Shestoi Mezhdunarodnyi Mezhdistsiplinarnyi kongress. «Neironauka dlia meditsiny i psikhologii». Sudak, Krym, Ukraina, 5-15 iiunia, 275.

27. Fedii O. A. (2007). Estetoterapiia. Kyiv, 247.

28. Shepovalnikov A. N., Egorov M. V. (2015). Izmenenie prostranstvennoi organizatsii kolebanii biopotentsialov kory bolshikh polusharii mozga u detei pod vliianiem muzyki. Fiziologiia cheloveka, 41, 6, 5-16.

Стаття надійшла до редакції 17.05.2019 p. 